\title{
Aproximación psicopatológica a El Quijote (según la nosología psiquiátrica actual)
}

RESUMEN: Se analiza la psicopatología de Don Quijote y se revisan los estudios previos sobre el personaje, tanto desde la perspectiva médica como la literaria. Considerando el enfoque de la nosología psiquiátrica actual, Don Quijote cumpliría criterios para un Trastorno Delirante y esto se argumenta en base a la génesis del delirio, la sintomatología y los rasgos formales del delirio. Asimismo, se propone el diagnóstico de Trastorno Psicótico Compartido para la pareja protagonista ( Don Quijote y Sancho).

PALABRAS CLAVE: Psicopatología, Don Quijote, Trastorno Delirante, Trastorno Psicótico Compartido

\section{Introducción.-}

Hay tantas cosas que animan a pensar y leer sobre el Quijote que resulta comprometido escribirlas a modo de ejercicio justificativo. Seguramente, esté influyendo estar ante la obra de ficción literaria más relevante de la historia de la humanidad. No es un aventurado pensamiento personal, es una certeza de muchos. El pasado mes de mayo, el Instituto Nobel y el Club del Libro Noruego hicieron públicos los resultados de una encuesta entre un grupo de 100 escritores de 54 paises, quienes eligieron a la novela de Miguel de Cervantes como la mejor obra literaria con un $50 \%$ más de votos que En busca del tiempo perdido de Marcel Proust, que fue la segunda más votada.
ABSTRACT: Psychopathology of Don Quixote is analysed and previous studies about the character are reviewed, from the medical as from the literary point of view. Seen from the current nososlogy perspective, Don Quixote would fullfil criteria for a Delusional Disorder and this is argumented on the base of the delusion's genesis, synthomatology and delusion's formal treats. Furthermore, the diagnose of Shared Psychotic Disorder is proposed for the main characters ( Don Quixote and Sancho).

KEY WORDS: Psychopatology, Don Quixote, Delusional Disorder, Shared Psychotic Disorder.

Pero más allá del influjo de los escritores, críticos y estudiosos literarios, nuestra postura nos lleva a reconocer vericuetos personales. Creemos que Cervantes inventa la ternura, probablemente apoyado en El Lazarillo de Tormes previo. Levanta una cartografía de las emociones humanas sobre dos personajes que se escuchan de verdad, que discuten las cosas para, finalmente, enloquecer juntos. ¿ Acaso existe algún ejemplo semejante en la historia? Ni Sócrates y sus discípulos practican esa dialéctica. Incluso Shakespeare, paradigma de la tragedia, de las pasiones, lo es de puertas a dentro. Jamás de una dialéctica amorosa y real, como lo hacen el caballero y Sancho. Diríase incluso que esta novela está centrada en la 
emotividad. Para Cervantes, las emociones son transformaciones mágicas del mundo.

Hablemos también de otra dialéctica, entre lo real y lo imaginado, sus deslizamientos de la ficción a la realidad a lomos de la ironía y viceversa. Una ironía elegante que evita lo macabro y lo escatológico.

Finalmente, consideremos que Cervantes es una maravillosa anticipación(1). Sus palabras, sus obras, son culpables, en parte por supuesto, de las creaciones de escritores (Borges, Dostoevski, Joyce, Twain); músicos (R. Strauss) o pintores (Picasso) es enorme y sobradamente conocido. Sin embargo, apenas se ha apreciado la influencia de la obra cervantina en algunos personajes clave de la psiquiatría como Freud o de las neurociencias como Cajal. A los veintisiete años, Freud escribió a su futura esposa, Martha Bernays, la profunda huella que dejo en él la lectura en español de las obras de Cervantes durante su infancia. Sobresalen, el interés por los diálogos de dos perros, Cipión y Berganza (Coloquio de los perros) donde básicamente uno de ellos cuenta su vida y el otro escucha, y la identificación con Don Quijote un personaje capaz de luchar hasta la locura por sus sueños. Durante esos años, Freud se debatía entre seguir sus investigaciones en neurociencias y convertirse en un científico moderno (ideal que veía imposible) o dedicarse a la práctica médica privada (Sancho como principio de realidad).

Cajal descubrió a los doce años "Don Quijote" desagradándole un héroe metido en tristes reveses y un final infeliz. Esta primera impresión cambió radicalmente a lo largo de su vida de manera que en sus textos de pensamiento son frecuentes las citas cervantinas. En 1905, un año antes de recibir el Premio Nobel de Medicina y Fisiología, leyó un discurso en el Colegio de Médicos de San Carlos titulado "Psicología del Quijote y el Quijotismo" donde considera a Don Alonso Quijano "un ideal de humanidad, de magnanimidad y de justicia" y advierte que estos ideales deben estar siempre presentes en el verdadero científico. Por aquel entonces, Cajal formaba parte de un movimiento regeneracionista en España que abarcaba a la ciencia y a la educación pero del que salió pocos años después desengañado y cansado de adversidades. En este sentido, su vida y su obra fueron un ejemplo de quijotismo.

Cervantes escribe su obra maestra El ingenioso hidalgo Don Quijote de la Mancha en un momento histórico que deja atrás un siglo de grandes cambios sociales y culturales. La nueva cosmovisión surgida en el Renacimiento sitúa al hombre en el centro de su atención e inaugura el pensamiento científico moderno, enfatizando la observación de la realidad como medio esencial para el avance del conocimiento. Esta es la actitud que impregna a Cervantes a la hora de reflejar en su novela un universo de personajes y situaciones de hondo realismo. El retrato de la locura en su personaje principal, Don Quijote, obedece a la misma agudeza descriptiva que despliega el autor en toda la obra y sitúa a Cervantes como uno de los más astutos observadores de la humana normal y enferma en su época.

Nada nos permite deducir que el autor tuviera conocimientos médicos específicos para describir, de una forma tan fiel, lo que hoy podría definirse dentro 
de algunas categorías diagnósticas de las enfermedades mentales, ya que las nociones sobre la enfermedad mental eran entonces confusas y precarias.

Autores como R. Salillas, que más adelante abordaremos, defienden que Cervantes conoció el famoso libro de Huarte de San Juan Examen de Ingenios, motivo por el cual el Don Quijote recibe el calificativo de "ingenioso", que no "loco". No obstante, la descripción psicopatológica del trastorno delirante en el protagonista sorprende por su agudeza y fidelidad a la realidad, y esto no parece resultar de la lectura de ningún tratado "psiquiátrico" de la época, ya que no existían como tal. En nuestra opinión, Cervantes debió de tomar el modelo para la locura de su personaje directamente de la realidad.

Por tanto, Cervantes ocuparía un puesto de honor entre los autores de su época que dedicaron su interés a la descripción de la enfermedad mental y cabe calificarle como uno de los más finos observadores de la conducta humana en la historia.

\section{Material y Método.-}

La fuente para el trabajo ha sido la novela de Cervantes El Ingenioso Hidalgo Don Quijote de la Mancha, en las ediciones a cargo de Francisco Rico (Edición del Instituto Cervantes, 1998 y que dispone de una versión beta en CD), Martín de Riquer ( Edición del XXV Aniversario de Círculo de Lectores, 1987) y John Jay Allen ( Edición Letras Hispánicas, Cátedra, 2000).

La obtención de la bibliografía secundaria fue una de las limitaciones surgidas al realizar este trabajo, ya que la recuperación de material publicado en torno al tema fue compleja, debido a su vasta extensión y a que se remonta hasta los inicios del S. XIX. Se hizo necesario establecer unos criterios de recogida precisos para evitar al máximo los posibles sesgos.

Las bases de datos utilizadas fueron ISOC, MLA International Bibliography y Medline.

Para la selección de aquellos artículos que más pudiesen estar relacionados con el tema de nuestro interés, recurrimos a los siguientes descriptores: quijote, quixote, psicopatología, psiquiatría, psicología, trastorno, mental, enfermedad, alienado, locura, madness, monomanía, demencia, delirio, paranoia, melancolía y depresión. Se obtuvieron en una primera selección 65 artículos. Tras descartar aquellos títulos repetidos o que se alejaban del contenido de nuestro estudio, la cantidad final de artículos fue de 13 artículos.

Con el material obtenido se elaboró un índice de materias, se abordó el análisis de los artículos, libros, notas y referencias para poder profundizar en su contenido. Se utilizaron, mediante fichas de trabajo, las técnicas tradicionales de análisis de texto.

\section{Psicopatología de El Quijote}

1.Estudios previos sobre la psicopa-tología de El Quijote

\subsection{Aproximación de la crítica literaria \\ "De cuantos comentadores caen} sobre el Quijote, no los hay más temibles que los médicos. Al punto se meten a escudriñar de qué especie era la locura de Don Quijote, su etiología, su sintomatología y hasta su terapéutica. 


\section{¿Que Don Quijote está loco?} Bien, ¿ y qué?"(2).

En este comentario de Unamuno queda sintetizado de manera precisa el punto de vista que defienden todos aquellos críticos de la obra de Cervantes que no pertenecen al área médica. Ni siquiera le conceden a la locura de Don Quijote verosimilitud suficiente para permitir un análisis clínico. La contemplan como un mero recurso técnico de Cervantes cuyos objetivos son de orden literario.

Diego Martinez Torrón, en su reflexión sobre la locura de Don Quijote publicada en Anales Cervantinos ( 1998) (3), descarta que el caso del hidalgo manchego corresponda realmente con el de un enfermo mental en base a que existen momentos de manifiesta lucidez en el personaje, como se observa en el Cap. XVIII cuando el hijo del Caballero del Verde Gabán examina a Don Quijote y concluye "No le sacarán del borrador de su locura cuantos médicos y buenos escribanos tiene el mundo: él es un entreverado loco, lleno de lúcidos intervalos". Según el autor, cabe destacar que Don Diego y Lorenzo han estado dudando de su estado ya que "Don Quijote alterna sesudas razones de elevada espiritualidad con la monomanía por la caballería andante" (4). En este punto se abre el debate entre este género de críticos cervantinos y los médicos, ya que éstos últimos cuentan con argumentos clínicos para considerar que la locura del personaje no queda descartada de esta forma.

Roger Bartra, en su último estudio antropológico sobre la melancolía en la España del Siglo de Oro (5), dedica un ensayo a la "melancolía" de Don Quijote, entendida ésta en un sentido amplio como enfermedad mental en general. Este autor tampoco le concede al trastorno del personaje un sentido real, sino que lo entiende como "un personaje artificialmente triste que imagina toda clase de ilusiones para consolarnos, hasta conseguir que el mundo alrededor organice y represente para él los simulacros cómicomelancólicos que dan vida a la novela: hasta que llega el bachiller y, mediante otro simulacro, cura la tristeza artificial del hidalgo y lo precipita al lóbrego abismo de una melancolía terminal." Sólo este último género de enfermedad que acaba con su vida tiene un carácter real y devastador.

Vicente Gaos, en el volumen III de su edición de Don Quijote (1987) (6), señala: "Los psiquiatras y otros críticos que juzgan a Don Quijote esquizofrénico, paranoico, etc., se den o no cuenta de ello, incurren en el mismo error del personaje que estudian: confunden realidad y ficción (...)" y a continuación añade "En el Quijote-único lugar donde en rigor cabe estudiarla-la locura del protagonista es, ante todo, un recurso técnico, un motivo funcional y estructurante de la novela. Si Don Quijote no estuviera loco, no habría Quijote. (7)"

¿Cuáles son los objetivos que persigue Cervantes con el artificio de locura que refleja en su personaje? Se han señalado múltiples, tantos casi como críticos se han acercado a la obra cervantina a los largo de los cuatro siglos que distan de su primera edición. Las tres líneas básicas de interpretación que sigue la crítica literaria se pueden sintetizar en este comentario de Sancho:

"En lo que toca-prosiguió Sancho- a la valentía, cortesía, hazañas y asunto de vuestra merced, hay dife- 
rentes opiniones: unos dicen: "Loco, pero gracioso"; otros "Valiente, pero desgraciado"; otros: "Cortés, pero impertinente"(8).

Los primeros lectores del Quijote lo vieron "loco, pero gracioso", se centraron en el aspecto paródico de la novela y la locura del personaje serviría meramente como recurso para criticar la literatura caballeresca de la época, tendría un mero propósito satírico.

En una segunda etapa iniciada en el S. XVII, los lectores empiezan a identificarse con el personaje, quien es "valiente pero desgraciado". Esta corriente llega a su culminación con la interpretación de los románticos alemanes en el S. XIX, que idealizan a Don Quijote y ven en él al "Caballero de la Fe", la fuerza espiritual de las aspiraciones humanas. Descubren en el Quijote un simbolismo de la relación entre el espíritu humano y la realidad.

Finalmente, el S. XX abre la gama de puntos de vista. Básicamente, el "cortés, pero impertinente" caballero es calificado de anticonformista, iconoclasta y revolucionario. También hay quien lo ve como relativista, erasmista, hombre barroco, contrarreformista e incluso hombre de la Edad Media. Este gran abanico de perspectivas se explica por la gran complejidad del mundo creado por Cervantes (9).

\subsection{Aproximaciones médicas al Quijote}

La tradición de estudios clínicos sobre el personaje literario de Don Quijote es larga, como no podía ser menos tratándose de la obra más leída de la literatura occidental y que mayor volumen de literatura crítica ha generado a lo largo de sus cuatro centurias de existencia. Es conocida la afición de los médicos por valorar clínicamente a personajes de ficción literaria, atribuyéndoles para ello una realidad biológica y humana.

Luis S.Granjel, en una completa revisión sobre el tema (10), traza una trayectoria iniciada en el S. XVII por el precursor de la medicina moderna Sydenham y alcanza hasta Vallejo Nágera en 1958 con su Apología de las patografías cervantinas (11). Sydenham ( 1624-1689) es conocido por formular el concepto inductivo de especie morbosa o entidad nosológica, noción básica de la patología moderna. En una ocasión, un noble preguntó a Sydenham qué libro de medicina le aconsejaba. La respuesta fue "Lea Don Quijote, que es un libro muy bueno; yo no me canso de leerlo". Según López Piñero (12), la anécdota responde al rechazo por parte del autor de la patología hasta entonces existente, así como refleja el prestigio de la obra cervantina en la Inglaterra de esa época.

Los médicos cervantistas se extienden dentro y fuera del país, siendo numerosos los profesionales franceses que se interesan por el personaje cervantino en el S. XIX, especialmente (13). Esto coincide con la línea de estudio iniciada por Pinel y Esquirol, quienes consideraron al hidalgo manchego como ejemplo literario del cuadro clínico de monomanía. Incluso Hernández Morejón, primer alienista español en comentar la obra de Cervantes, reedita en Francia en 1862 su obra Bellezas de medicina práctica descubiertas en el Ingenioso Caballero Don Quijote de la Mancha (14).

En definitiva, todos los médicos que han estudiado la obra de Cervantes coinciden 
en considerar a Don Quijote como un enfermo mental. Su diagnóstico es de monomanía o paranoia según las corrientes psiquiátricas vigentes en cada época, es decir, antes y después de la revolución kraepeliniana. Asimismo, todos elogian el valor de la novela como puntual historia clínica y el acierto de Cervantes en describir de forma tan fiel un cuadro clínico que recibiría su designación científica tres siglos después.

La forma de abordar el estudio psicopatológico del personaje libresco sigue dos orientaciones básicas entre los autores: el estudio clínico-psiquiátrico y el estudio biotipológico.

\section{2.a. El estudio clínico-psiquiátrico. \\ Diferentes psiquiatras conceden} a Don Quijote realidad histórica como premisa para interpretar su trastorno mental y elaboran su historia clínica según las doctrinas científicas que circulan en su época. El estudio está centrado en la etiología, sintomatología, evolución clínica y abordaje terapéutico, sin dejar de proponer un diagnóstico preciso para la afección de Don Quijote que se entronca en la nosología psiquiátrica de la época. Los autores más relevantes en España (15) son:

\section{A. Hernández Morejón}

En 1832 publica Bellezas de medicina práctica descubiertas en el Ingenioso Caballero Don Quijote de la Mancha (16). Su estudio, donde no faltan elogios para Cervantes como audaz observador clínico, concluye con el diagnóstico de monomanía para el hidalgo enloquecido. Lo argumenta siguiendo los cánones de una historia clínica completa, donde expone la etiología, la enumeración de síntomas, el curso evolutivo y el abordaje terapéutico.
Como causas predisponentes no falta la mención al temperamento, que define como "bilioso y melancólico", la edad de aparición ( alrededor de los 50 años), los hábitos alimenticios, época de aparición de los episodios clínicos ( "raptos de locura" en verano y otoño), la pasión amorosa que lo enajenó y finalmente, cómo no, el efecto pernicioso de la lectura en horas de vigilia continuada. El propio Cervantes explicita esto último cuando viene a explicar que "él se enfrascó tanto en su lectura, que se le pasaban las noches leyendo de claro en claro, y los días de turbio en turbio; y así, del poco dormir y del mucho leer se le secó el celebro de manera que vino a perder el juicio"(17).

Para Hernández Morejón, es muy acertada la manera como el autor finaliza el curso de la dolencia mental, ya que aparece finalmente un acceso de melancolía seguido de un cuadro orgánico.

También dedica este psiquiatra un capítulo a comentar los abordajes terapéuticos de aquellos que intentaron devolverle el juicio a Don Quijote: el cura, el barbero y el bachiller Sansón Carrasco. Según el autor, Cervantes está anticipando el "tratamiento moral de las enajenaciones del alma" que defendían Pinel y su escuela desde el inicio del S. XIX.

En definitiva, nada le falta según Hernández Morejón a la novela si se considera como una historia clínica, salvo la misma autopsia que vendría a completar una descripción científica de la "enajenación del alma", ya que "hay orden, hay claridad, hay imitación de la naturaleza, y hay en fin una aplicación de medios morales, más ingeniosos y 
adecuados a la causa de la locura, que cuantos hubiera podido imaginar el mismo Pinel y otros que le han precedido".

\section{E. Pi y Molist}

Este autor, conocido por su labor al frente del Hospital de la Santa Cruz en Barcelona, fue uno de los más prestigiosos psiquiatras de la época. Influido por la tradición francesa, especialmente por Esquirol, elaboró un trabajo sobre la monomanía que introdujo en su discurso de entrada en la Real Academia de Medicina de Barcelona (18). Su principal trabajo científico-literario es Primores del Don Quijote en el concepto médicopsicológico y consideraciones generales sobre la locura para un nuevo comentario de la inmortal novela (19), que publica en 1886.

Se trata de un intento de análisis e interpretación del personaje cervantino que pretende ser definitivo y que ocupa una extensión de casi 500 páginas. Se propone hacer comprensibles por vía médica su personalidad y aventuras y para ello comenta, episodio tras episodio, las andanzas del personaje interpretándolas como manifestaciones típicas del trastorno que padece.

El diagnóstico que hace este psiquiatra va en la línea de sus predecesores y califica la monomanía de Alonso Quijano como "de engrandecimiento, caracterizada por un concepto delirante fijo, primario, fundamental o constitutivo, y otros secundarios, ya fijos, ya fugaces; por ilusiones de la vista, una del tacto y otra del olfato, y alucinaciones del oído, aquéllas y éstas accidentales; y por una lesión constante de la sensibilidad afectiva en forma de erotomanía (20)". El autor entiende por idea delirante primaria la de "imaginarse convertido en caballero andante" y cree que "de esta idea falsa fueron sucesivamente derivándose las demás”, que él denomina conceptos delirantes secundarios. Entre estos últimos figuran las promesas a Sancho y el amor a Dulcinea (idea delirante erotomaniaca), pero señala que eran "aunque secundarios, tan fijos como el fundamental".

No deja de mencionar la ausencia de "abulia ni depresión de la inteligencia...ni impulsos insólitos", como criterios a favor de un diagnóstico de monomanía, ya que se preserva la personalidad y capacidades intelectuales ("locura razonante" de los franceses).

También argumenta que "puesto que las ideas delirantes predominaban sobre los fenómenos de la sensibilidad externa,..., la monomanía de Don Quijote ha de diagnosticarse de intelectual". Más adelante, no obstante, contempla la posibilidad de que se califique "también de afectiva la vesania" ya que una de las ideas delirantes secundarias "dio origen a un delirio erotomaniaco".

En referencia al curso evolutivo, menciona que "aunque esencialmente lúcida esta psicopatía, no tuvo en todo su curso un intervalo lúcido, sino dos remisiones, en los espacios de tiempo en que el enfermo estuvo quieto en casa, después de sus salidas primera y segunda". El modo ideado por Cevantes para finalizar el cuadro clínico le parece a Pi y Molist muy compatible con la realidad clínica y esto le fascina al autor, ya que lo ha observado comúnmente en lipemaníacos (melancólicos) y maniacos. En el personaje "la pasión melancólica consecutiva a la frenalgia perturbó hondamente el sistema 
psíquico, y vino...dando origen a una enfermedad incidental". A este final favoreció " la edad provecta y su constitución bilioso-nerviosa".

Al igual que su precursor español, Hernández Morejón, al que dedica un análisis crítico inicial, Pi y Molist menciona los predisponentes ( "constitución frenopática") y la terapéutica "moral”, que también elogia. Opina que "ahora, en un loco de la misma especie, intentaría un alienista" la misma terapéutica "que en algún modo cabe calificar de homeopática o sustitutiva", ya que el bachiller Sansón Carrasco usa "del semejante por el semejante", " de la caballería por la caballería".

El psiquiatra catalán, dentro de su tono laudatorio hacia Cervantes, se permite alguna crítica en torno al modo en que la locura del personaje queda expuesta en detrimento de su veracidad clínica, pero "aquellas imperfecciones lejos de rebajar, realzan el mérito de Cervantes" ya que "hízolo por inspiración, no por estudio"y no cree en la posibilidad de influencias médicas para la génesis de la novela. Con todo, señala que " Cervantes, con no haber sido alienista, podría figurar en los anales médico-psicológicos al lado de Esquirol".

\section{R. Royo Villanova}

Este catedrático de la Universidad de Medicina de Zaragoza hizo su aportación al estudio de Don Quijote con ocasión de las dos conmemoraciones cervantinas que tuvieron lugar en $1905 \mathrm{y}$ 1916, con el 3er centenario de la publicación de la primera y segunda parte de la novela, respectivamente. En 1905 publica el ensayo La locura de Don Quijote (21) y en 1916 publica el trabajo Don Quijote, licenciado en Medicina (22).

$\mathrm{El}$ autor concede al hidalgo realidad histórica en un intento de interpretación clínica de su dolencia, "hablar del loco Don Quijote como podría hacerlo de otro loco cualquiera, redactando su historia clínica a la luz de la ciencia actual". Así, se comentan los antecedentes descubiertos en la locura del personaje, los signos, morfológicos y psíquicos, evidenciados en su trastorno mental así como su curso evolutivo.

El modo de abordar el tema es similar al de sus precursores en el S. XIX, solo que nos encontramos en una época posterior a la revolución kraepeliniana y el psiquiatra alemán ya ha reformulado el proceso mental de monomanía en paranoia. El diagnóstico que proporciona Royo Villanova es, por tanto, el de “ paranoia crónica o delirio sistematizado o parcial de tipo expansivo, forma megalómana y variedad filantrópica".

\section{2.b. El estudio biotipológico}

Los autores que siguen esta línea de aproximación a la novela cervantina se centran en señalar las características distintivas de la constitución y temperamento en los personajes, especialmente en su protagonista Don Quijote.

\section{R. Salillas}

Este autor, que se autocalificaba humorísticamente como "médico en desuso", participó también en los actos conmemorativos del tercer centenario de la obra en 1905, pronunciando un discurso en el más solemne de todos los eventos: el organizado por el Colegio de Médicos madrileño con apoyo gubernamental. 
Salillas intervino junto a Ramón y Cajal, José Gómez Ocaña, Blas Lázaro Ibiza, Angel Pulido y Federico Olóriz (este último, en los "caracteres físicos del Quijote", expuso sus conocimientos antropológicos para recomponer la estampa humana del personaje). Su aportación la recoge posteriormente el libro $U n$ gran inspirador de Cervantes. El doctor Juan Huarte y su "Examen de Ingenios", publicado en 1905. (23)

La originalidad del autor consiste en proponer una sugerente hipótesis sobre las influencias que pudieron darse en la génesis de la novela, en concreto la modalidad de trastorno mental que expone un contemporáneo de Cervantes muy difundido en la época: Huarte de San Juan. Su famoso Examen de Ingenios para las Ciencias, editado en 1575, pudo haber llegado a manos de Cervantes, de ahí la atribución de "ingenioso hidalgo"para el personaje, que no "loco".

Según Salillas, "la definición de las causas de la locura de Don Quijote está hecha con arreglo a la doctrina de las destemplanzas" Esto lo prueba el autor con testimonios ofrecidos en la Galatea, el Persiles y Segismunda y la figurada historia del licenciado Vidriera.

Huarte proponía que el predominio de algún humor, una "destemplanza", producía las diferencias de ingenio, y la locura, según esta hipótesis, era "un modo de ingenio".

\section{J. Goyanes}

El doctor José Goyanes, con prólogo de Marañón, publica en 1932 Tipología de El Quijote. Ensayo sobre la estructura psicosomática de los personajes de la novela (24). Según señala
Marañón, los métodos de estudio de este autor son insólitos en la historia de las aproximaciones médicas a El Quijote, ya que se trata de una "investigación psicológica y psicosomática, rigurosamente científica".

Goyanes, como sus predecesores, no deja de introducirse en el análisis del trastorno mental del personaje, diagnosticándolo de un "delirio de interpretación o paranoia". Esto lo lleva a cabo tras comentar el comportamiento de los protagonistas novelescos y prestando especial atención al estudio de las perturbaciones sensoriales del hidalgo manchego. Finalmente, señala el comportamiento erótico de Don Quijote y lo interpreta, bajo los supuestos del psicoanálisis, como el resultado de la represión sexual.

No obstante, la aportación original de este autor en el acercamiento a la figura cervantina radica en su estudio biotipológico, que él mismo justifica como "algo que quizá no pueden traer los literatos de oficio, que es aquello que la medicina de hoy sabe de la relación entre soma o cuerpo y alma o espíritu, de la correlación psicofísica en cada persona o personaje (25)". Goyanes califica a Don Quijote, utilizando la tipología kretschmeriana, de leptosomático: psicológicamente se trata de un idealista propenso a la sublimación de sus impulsos. El autor también se sirve de la clasificación de Jung, según la cual sería un introvertido, "un sujeto con la mente dirigida hacia dentro, dominando en él la subjetividad, el mundo de la fantasía" (26), y de Jaensch, que concibe a Don Quijote como un hipertiroideo próximo al tipo "basedowoide", donde "la afectividad, lo mismo que la capacidad de emoción, es muy fuerte" (27). Respecto a Sancho, el autor señala 
que su biotipo sería el de un pícnico y su temperamento el ciclotímico.

La conclusión que traza Goyanes al final de su reflexión rigurosa y pormenorizada, es que en la locura del hidalgo "la predisposición radica en su constitución biotípica; la patogénesis la hallamos en la represión continua del instinto, de la líbido; la plasmación o protoplástica, en la lectura de los libros de caballerías" (28). Y no falta el elogio a la capacidad de Cervantes como hábil observador de la realidad, ya que "acierta a interpretar por intuición procesos biológicos que un estudio posterior objetivo y científico viene a confirmar" (29).

\section{Gutiérrez Noriega}

Este psiquiatra peruano publica en 1944 Contribución de Cervantes a la Psicología y la Psiquiatría (30) y en 1947 La personalidad y el carácter en la obra de Cervantes (31). Al igual que Goyanes, este autor se centra en señalar a Cervantes como precursor de las teorías biotipológicas de Kretschmer y examina médicamente los personajes de Sancho y Don Quijote.

El núcleo de su reflexión radica en señalar que "la contribución de Cervantes al estudio de las enfermedades mentales no es de orden escolar o normativo. $\mathrm{Su}$ acierto consiste en la invención de grandes figuras representativas, que reproducen tan fielmente y con tal variedad de detalles las características de ciertos tipos psicológicos o de ciertos desórdenes mentales, que parecen observaciones directas de la realidad y a la vez denotan una capacidad muy notable para captar lo que es fundamental en cada caso".
Según el autor, algunas novelas de Cervantes, y no sólo El Quijote, revelan una precisión descriptiva tal, que "son verdaderos historiales de tipos psicológicos o de enfermos mentales".

\section{El trastorno delirante}

El tno. delirante se define como un trastorno psiquiátrico en el cual los síntomas predominantes son ideas delirantes. Inicialmente se le denominó paranoia y el término, que deriva de dos palabras griegas que significan "junto a" y "mente", lo introdujo Kahlbaum en 1863 para referirse a una enfermentad mental parcial que sólo afectaba al intelecto. En 1818, Heinroth ya había introducido el concepto básico del trastorno en psiquiatría y Esquirol, en 1838, se había referido al cuadro delirante sin afectación del razonamiento lógico ni de la conducta general bajo el término de monomanía (32).

Kraepelin, en la $6^{\text {a }}$ edición de su famoso Tratado (1899) (33), aporta una definición de la paranoia, que se impuso en todo el mundo, para delimitarla de la dementia praecox (hoy esquizofrenia) y de la locura maníaco-depresiva (hoy trastorno bipolar) (34). Para Kraepelin, "la paranoia se caracteriza por el desarrollo insidioso, a partir de causas internas, de un sistema delirante durable e inquebrantable, que coexiste con el total mantenimiento de la claridad y el orden del pensamiento, la voluntad y la acción.” Según Kraepelin (35), la temática de las ideas delirantes gira en torno a dos polos básicos: el perjuicio (persecución, celos, hipocondría) y la grandeza (invención, filiación, mística, erotomanía). No existen alucinaciones, pero sí intuiciones delirantes, interpretaciones, falseamiento de los recuerdos e 
ideas de referencia. Esta definición clásica sigue conteniendo, con toda claridad y vigencia, los términos esenciales de lo que, un siglo después, se inscribe en las nosologías actuales dentro del grupo de los "trastornos delirantes" (DSM IV) o de los "trastornos por ideas delirantes persistentes" (CIE 10).

En nuestra opinión, éste es el diagnóstico más apropiado para el personaje literario que nos ocupa, ya que su locura reúne todos los síntomas compatibles con el trastorno delirante. También los clásicos, empezando por Pinel a principios del S. XIX (36), coincidieron en opinar que la monomanía, hoy trastorno delirante (37), era el diagnóstico más acorde para Don Quijote.

\subsection{Génesis del delirio en Don Quijote}

Kretschmer, en su obra "El delirio sensitivo de referencia" (38), sostiene que los factores que determinan la aparición del delirio son el carácter, la vivencia y el medio social. Por tanto, el delirio aparece como resultado de un acontecimiento vital conmocionante, que impacta en una personalidad determinada, y bajo una influencia ambiental concreta.

Muchos son los autores que han descrito la personalidad del paranoico, pero Kretschmer ha sido el que más se aproxima en su análisis a los rasgos caracteriales de Don Quijote. Al describir la personalidad sensitiva y relacionarla con la vulnerabilidad para padecer un delirio de referencia, este autor habla de "ciertas naturalezas delicadas que no solo son muy profundamente receptivas y sensibles a sus vivencias, sino que las siguen elaborando interiormente, en silencio", sin que se trasluzca nada al exterior. Muestran "una extraordinaria blandura afectiva, debilidad y vulnerabilidad, y, por otro lado, cierta ambición y obstinación". Son "introvertidos, pero también asequibles y amables, humildes pero muy ambiciosos y con gran capacidad social" (39).

Pocos son los datos asequibles en la novela de Cervantes sobre la personalidad premórbida de su protagonista, ya que la acción arranca a partir del momento en que éste inicia los primeros síntomas de su enfermedad. No obstante, en su último capítulo, cuando el hidalgo habla desde la recobrada lucidez, se autodescribe como "Alonso Quijano, a quien mis costumbres me dieron renombre de Bueno" y Cervantes a continuación confirma que "en tanto que don Quijote fue Alonso Quijano el Bueno, a secas, y en tanto que fue don Quijote de la Mancha, fue siempre de apacible condición y de agradable trato, y por esto no sólo era bien querido de los de su casa, sino de todos cuantos le conocían" (40)

Respecto a la vivencia, Kretschmer menciona experiencias traumáticas que suelen ser conflictos derivados de actitudes afectivo-eróticas no asumidas por el sujeto y que, por ello, en virtud de su estricta conciencia moral, le suscitan intensos sentimientos de culpa (41). Para Kretschmer "la vivencia que hemos llamado, por ejemplo, "amor desgraciado", resulta fundamentalmente distinta según una forma vivencial subjetiva para las diversas personalidades psicopáticas", por tanto, para la personalidad sensitiva, un amor desgraciado constituye una "derrota vergonzosa", "la vivencia indignante hace al paranoico combativo" (42). 
No abunda la información sobre estos posibles antecedentes en la novela cervantina, pero al inicio de la obra conocemos que, a colación de la existencia de Aldonza Lorenzo, "en un lugar cerca del suyo había una moza labradora de muy buen parecer, de quien él un tiempo anduvo enamorado ( aunque, según se entiende, ella jamás lo supo ni le dio cata dello)" (43).

En cuanto al ambiente, Kretschmer entiende que los factores ambientales tan sólo son coadyuvantes en la génesis del delirio, pero cabe señalar que influyen situaciones de aislamiento, pequeñas poblaciones de moral estrecha y rígidos convencionalismos y un fuerte control social. Este debió de ser, sin duda, el contexto en el que transcurría la vida de Alonso Quijano dados los indicios que nos llegan en la novela de aquel "lugar de la Mancha de cuyo nombre no quiero acordarme”. Se trataba sin duda de una población rural de escasos habitantes bajo la oligarquía del cura local, donde imperaba la moral católica de la España del XVI.

2.2. Manifestaciones clínicas en Don Quijote

2.2.a. Descripción general de su estado mental

Lo más destacable de su estado mental, tal y como lo examinan el cura y el barbero tras la segunda de sus salidas, le muestra como una persona normal excepto por la presencia del delirio. Así "habló don Quijote con tanta discreción en todas las materias que se tocaron, que los dos examinadores creyeron indubitada- mente que estaba del todo bueno y en su entero juicio", pero, finalmente, el cura "mudando el propósito primero, que era de no tocarle en cosa de caballerías, quiso hacer de todo en todo experiencia si la sanidad de don Quijote era falsa o verdadera". Entonces es cuando el hidalgo manchego vuelve a mencionar su creencia en la caballería andante "que se junten en la corte para un día señalado todos los caballeros andantes que vagan por España" y su convicción de ser uno de ellos "caballero andante he de morir..." (44).

\section{2.b. Aspecto}

De todos es conocido el aspecto que ofrece este personaje literario, ya que su imagen ha llegado a convertirse en un icono universal. Sancho la recoge con acierto en el sobrenombre de El Caballero de la Triste Figura que elige para él. A la pregunta sobre esta ocurrencia, el escudero responde "porque le he estado mirando un rato a la luz de aquella hacha que lleva aquel malandante, y verdaderamente tiene vuestra merced la más mala figura, de poco acá, que jamás he visto; y débelo de haber causado, o ya el cansancio deste combate, o ya la falta de muelas y dientes". Más adelante añade "que le hace tan mala cara el hambre y la falta de muelas" (45).

\section{2.c. Alteraciones del pensamiento}

Alteraciones del contenido.

Constituyen el síntoma básico y característico del trastorno, en forma de ideación delirante. Se dan en forma de delirios, interpretaciones delirantes y falsas identificaciones. La temática delirante que predomina en el ingenioso hidalgo es la de grandiosidad, ya que mantiene la creencia 
de ser un famoso caballero andante, pero coexiste con la ideación de perjuicio. En el caso del “sabio encantador Frestón”, Don Quijote le describe como "grande enemigo mío, que me tiene ojeriza, porque sabe por sus artes y letras que tengo de venir, andando los tiempos, y le tengo de vencer, sin que él lo pueda estorbar, y por esto procura hacerme todos los sinsabores que puede" (46).

Asimismo, hay quien ha señalado la presencia añadida de un delirio erotomaniaco respecto a Dulcinea del Toboso (47), ya que, como la Duquesa le confronta en la segunda parte de la novela, de la historia "se colige, ..., que nunca vuesa merced ha visto a la señora Dulcinea, y que esta tal señora no es en el mundo, sino que es dama fantástica; que vuesa merced la engendró y la parió en su entendimiento". A lo que responde Don Quijote "Ni yo engendré ni parí a mi señora, puesto que la contemplo cómo conviene que sea: una dama que contenga en sí las partes que puedan hacerla famosa en todas las del mundo" (48).

La estructura formal del delirio será ampliamente analizada más adelante.

Las interpretaciones delirantes, junto con las ilusiones visuales y de otros tipos, son las alteraciones psicopatológicas que van extendiendo y consolidando su delirio. Se dan en ocasiones como la del capítulo LII de la primera parte, en la "rara aventura de los disciplinantes", en la que "Don Quijote, que vio los estraños trajes de los disciplinantes, sin pasarle por la memoria las muchas veces que los debía haber visto, se imaginó que era cosa de aventura, y que a él sólo tocaba, como a caballero andante, el acometerla" (49).
En cuanto a las falsas identificaciones, han sido descritas por Pi y Molist bajo el calificativo de "trueco de personalidad", que según este autor "se asemeja a idea delirante". Las sufre Don Quijote tras sendos episodios de agitación y alucinaciones visuales, en los que el cura y el barbero acuden a atenderle. En el capítulo VII de la primera parte, tras una supuesta batalla contra “don Roldán”, en la que Don Quijote iba "dando cuchilladas y reveses a todas partes, estando tan despierto como si nunca hubiera dormido", el hidalgo loco se dirige al cura confundiéndole con el "señor arzobispo Turpín" y confunde asimismo su propia identidad "mas no me llamaría yo Reinaldos de Montalbán si, en levantándome de este lecho, no me lo pagare” (50). Más adelante se da un episodio similar, solo que esta vez "no tenía los ojos abiertos, porque estaba durmiendo y soñando que estaba en batalla con el gigante". Sucede en el capítulo XXXV de la primera parte, y "tenía ya el cura de las manos a don Quijote, el cual, creyendo que ya había acabado la aventura, y que se hallaba delante de la princesa Micomicona, se hincó de rodillas delante del cura" y se dirige a él como "vuestra grandeza, alta y fermosa señora” (51).

Alteraciones formales del pensamiento.

No se dan en este tipo de enfermos, si bien algunos pueden estar verborreicos y ser circunstanciales o idiosincrásicos en su lenguaje cuando hablan de sus ideas delirantes (52). Esto es lo que observamos en los discursos del hidalgo manchego, como lo ejemplifica el capítulo XXXII de la segunda parte, que recoge 
"la respuesta que dio don Quijote a su reprehensor": un eclesiástico en la casa de los duques, donde están invitados Don Quijote y su escudero, que le confronta con la falsedad de sus delirios. El ingenioso hidalgo "con semblante airado y alborotado rostro" "temblando de los pies a la cabeza como azogado, con presurosa y turbada lengua" lanza una larga réplica argumentando la veracidad de su condición de caballero andante, con un discurso prólijo y divagatorio en el que sobreabundan los datos accesorios en torno a la idea directriz, sin llegar a perderla. Los rodeos y los detalles innecesarios, junto con el léxico y las fórmulas arcaizantes, le dan un tono de pedantería que asombra a todo el auditorio (53).

\section{2.d. Alteraciones perceptivas}

Por definición, los pacientes con un trastorno delirante no sufren alucinaciones importantes. Los criterios nosológicos actuales incluyen la posibilidad de que se den experiencias alucinatorias olfativas o táctiles si son acordes con el delirio y, en general, son pocos los delirantes que tienen otras alucinaciones, casi siempre auditivas más que visuales.

Ya hemos señalado como Kraepelin apuntaba que en la paranoia "no existen alucinaciones, pero sí intuiciones delirantes, interpretaciones, falseamiento de los recuerdos e ideas de referencia” (54). Esto es lo que describe Cervantes en su protagonista y ya en 1881 lo analizaba Pi y Molist en su libro sobre Don Quijote (55). Según este autor "alucinaciones padeció pocas, con relación a las ilusiones, y fueron principalmente del oído, aunque algunas de la vista y una del tacto; si bien estas últimas mejor se llamarían conceptos delirantes", describiendo a continuación lo que hoy calificaríamos como interpretaciones delirantes.

En nuestro estudio, hemos hallado ejemplos abundantes de ilusiones (falsas interpretaciones de los estímulos provenientes de un objeto externo). También se da algún caso de alucinación (percepción sin estímulo externo vivenciada como verdadera) (56).

\section{Ilusiones visuales}

Son las más abundantes en la psicopatología del personaje. En el capítulo II de la primera parte, donde el hidalgo llega a la venta y la confunde por castillo "con sus cuatro torres y chapiteles de luciente plata", es un ejemplo, como lo son también el hecho de confundir a las "dos destraídas mozas" por "hermosas doncellas", al porquero que, para recoger su manada, tocó un cuerno, por "algún enano que hacía señal de la venida del Caballero" (57), los molinos de viento por "desaforados gigantes" (58), los dos rebaños de ovejas y carneros por "un copiosísimo ejército” (59) y la vulgar bacía de azófar de un barbero lugareño por el “encantado yelmo de Mambrino” (60).

Ilusiones táctiles

En la venta de Palomeque, cuando la mal comprometida Maritornes topó con los brazos de Don Quijote, a éste le pareció de "finísimo y delgado cendal" la camisa de harpillera de la asturiana, "traía en las muñecas unas cuentas de vidrio; pero a él le dieron vislumbres de preciosas perlas orientales. Los cabellos, que en alguna manera tiraban a crines, él los marcó por hebras de lucidísimo oro de Arabia" (61). 
Ilusiones olfativas.

En el mismo episodio recién descrito, el aliento de Maritornes, que "olía a ensalada fiambre y trasnochada, a él le pareció que arrojaba de su boca un olor suave y aromático" (62).

Ilusiones auditivas.

Con motivo de la descripción de los dos ejércitos que Don Quijote creía ver en dos rebaños de ovejas, éste le increpa a Sancho “ ¿No oyes el relinchar de los caballos, el tocar de los clarines, el ruido de los atambores?", a lo que el escudero responde "no oigo otra cosa sino muchos balidos de ovejas y carneros" (63). $\mathrm{Pi}$ y Molist calificó esto como ejemplo de alucinación auditiva, pero más bien parece producto de una ilusión, ya que el estímulo auditivo existe en el espacio externo, pero queda distorsionado en la mente del ingenioso hidalgo.

Alucinaciones visuales y táctiles.

En el capítulo VII de la primera parte, tras el "donoso escrutinio que el cura y el barbero hicieron en la librería de nuestro ingenioso hidalgo", oyen a Don Quijote gritar en su aposento "jaquí, aquí, valerosos caballeros!" y le encuentran "levantado de la cama, y proseguía en sus voces y en sus desatinos, dando cuchilladas y reveses a todas partes, estando tan despierto como si nunca hubiera dormido” (64). Señala Pi y Molist a esto que "pocas palabras que valen por muchas para poner claramente en su punto el concepto de la verdadera alucinación” (65). Tras la supuesta batalla, Don Quijote dice estar quebrantado "porque aquel bastardo de don Roldán me ha molido a palos con el tronco de una encina". Resulta complejo discernir el tipo de alucinación a la que responde esto, si táctil o tan sólo visual. Tampoco resuelve la duda de si se ha acompañado de voces todo el episodio.

En un episodio similar relatado por la sobrina, ésta informa que, tras estar "dos días con sus noches" leyendo libros de caballerías, su tío "andaba a cuchilladas por las paredes...y el sudor que sudaba decía que era sangre de las feridas que había recebido en la batalla". Pi y Molist califica este fenómeno de alucinación táctil, pero pudiera ser de nuevo una mera alucinación visual.

\section{2.e. Estado de ánimo, afectividad \\ El ánimo del Caballero de la} Triste Figura es acorde en todo momento con el contenido delirante que predomine, si bien suele tender hacia la hipertimia debido a su ideación de grandeza. Así, se describe en él sintomatología maniforme que no llega a cumplir criterios para un episodio maniaco. Existe expansividad (la prometida ínsula para Sancho "bien podría ser que antes de seis días ganase yo tal reino...que viniesen de molde para coronarte por rey de uno de ellos"), conductas arrogantes, jactanciosas y temerarias ( como en el Cap. XVII de la segunda parte "De donde se declaró el último punto y estremo adonde llegó y pudo llegar el inaudito ánimo de don Quijote, con la felicemente acabada aventura de los leones") y una disminución de la necesidad de sueño ( "Duerme el criado y está velando el señor, pensando cómo le ha de sustentar, mejorar y hacer mercedes") (66) y de la ingesta. No faltan tampoco momentos en que predomina la 
suspicacia y la irritabilidad, siempre que se le confronte al caballero la veracidad de su delirio.

Sea cual sea la naturaleza del sistema delirante, en un paranoico siempre se puede percibir una depresión leve (67). Este es el caso de nuestro protagonista al final de su trayectoria novelesca, en que la recuperación de su juicio conlleva un desmoronamiento del ánimo y "fue el parecer del médico que melancolías y desabrimientos le acababan" (68).

\section{2.f. Sensorio y cognición}

En el trastorno delirante, tal y como lo recogen las definiciones clásicas y las actuales, se preservan todas las funciones mentales relativas a la capacidad cognitiva. Memoria, atención y otros procesos cognitivos están intactos. La orientación no se afecta a menos que el delirio haga referencia a su persona, al lugar o al tiempo.

En Don Quijote esto es así a lo largo toda la novela salvo por dos episodios, previamente descritos, en los que aparecen falsas identificaciones en el contexto de cuadros alucinatorios visuales e intensa agitación psicomotriz (69). Esto es compatible con la posible presencia de cuadros confusionales agudos intercalados en la evolución de su trastorno delirante. Algunos autores los han señalado para argumentar la hipótesis de un cuadro demencial de base en el hidalgo manchego, a favor de una posible enfermedad por cuerpos de Lewy (70).

\section{2.g. Juicio y percepción interna}

Los pacientes paranoicos no alcanzan nunca a tener conciencia de su patología, ya que muestran una convicción irreductible en sus delirios. Sobran los ejemplos sobre este aspecto en Don Quijote, ya que lo evidencian su conducta alterada y sus discursos a lo largo de toda la novela. Tan sólo al final, cuando recupera el juicio, llega a hacer una crítica razonable de toda la sintomatología padecida, dirigiéndose a Sancho para pedirle perdón "de la ocasión que te he dado de parecer loco como yo, haciéndote creer en el error en que yo he caído, de que hubo y hay caballeros andantes en el mundo" (71).

\subsection{Estructura formal del delirio en Don} Quijote

Jaspers propone un modelo conceptual que distingue entre forma y contenido del delirio (72). Según este autor, la estructura formal de los delirios es de gran utilidad en el diagnóstico diferencial de las enfermedades mentales (73). Esto es especialmente así cuando se trata de delimitar las características definitorias de las cuatro grandes entidades morbosas en que aparece sintomatología delirante: la esquizofrenia, la paranoia, la psicosis maniaco-depresiva y los trastornos cerebrales orgánicos. El contenido delirante persecutorio puede ser común a todas ellas $\mathrm{y}$, sin embargo, son las características formales del delirio las que distinguen a cada una de estas enfermedades en que aparece.

Como venimos señalando, en Don Quijote se dan los síntomas compatibles con el actual trastorno delirante, que nosológicamente entronca con la Paranoia de Kraepelin y que Jaspers entendería como "desarrollo paranoide". La descripción que aporta Cabaleiro (74) de este tipo de delirio, bajo la influencia de 
Henry Ey (75), señala ocho características formales que asimismo encajan con la sintomatología de Don Quijote.

\section{3.a. Carácter constitucional del delirio. \\ Con esta definición se indica que} existe una continuidad entre la personalidad del paranoico y el mismo delirio, es decir, no surge como algo "nuevo" que implique una ruptura biográfica en la persona que lo sufre. Este aspecto ha sido ya ampliamente descrito en el apartado precedente sobre la génesis del delirio en Don Quijote. Como dice Castilla del Pino "al delirio se "llega"y, por tanto, como error que es, como error en el modo de interpretar la realidad y su propia realidad como sujeto, en la biografía del delirante está la clave de por qué ha de adoptar una visión delirada de la realidad y por qué ésta tiene un carácter definitivo e incorregible. El delirio salva al delirante del sufrimiento que el estar en la realidad, y la aceptación de si mismo a que ella le obliga, le deparan" (76).

\section{3.b. Estructura afectiva del delirio.}

A diferencia de la esquizofrenia, donde la carga de afectividad inicialmente asociada a la idea delirante decrece llegando a la indiferencia afectiva, en los desarrollos delirantes ésta se mantiene a un alto nivel. Junto con la preservación de la personalidad propia del paranoico, éste se ve motivado a la acción.

Poco cabe decir respecto a cómo se cumple esta condición en Don Quijote, ya que la acción a la que se ve impelido por su locura es ampliamente conocida y la recoge una extensa novela. El hidalgo manchego se implica en un largo recorrido para "buscar las aventuras y a ejercitarse en todo aquello que él había leído que los caballeros andantes se ejercitaban, deshaciendo todo género de agravio" (77). Sobre la alta carga de afectividad asociada a esta idea delirante nos habla Cervantes cuando señala que "así, con estos tan agradables pensamientos, llevado del estraño gusto que en ellos sentía, se dio priesa a poner en efecto lo que deseaba" (78).

\section{3.c. Carácter secundario del delirio.}

Siguiendo a Jaspers, lo que hace primario a un delirio (como lo es el esquizofrénico) es que una percepción delirante adquiera una significación incomprensible de acuerdo con la personalidad y el contexto vital del paciente. No es esto lo que sucede en el caso que nos ocupa: como ya hemos señalado, el delirio de Don Quijote emana y se estructura paulatinamente a partir de sus rasgos de personalidad y de los acontecimientos vitales conmocionantes en su vida. La significación delirante añadida a lo que percibe es comprensible psicológicamente, se trata por tanto de la interpretación delirante de una percepción y no de un delirio primario sino secundario ( ya que es comprensible). Tomando el modelo de Jaspers de forma estricta, el delirio que no es procesal o primario se considera una mera idea deliroide y no un auténtico delirio. No obstante, lo que se conocen como "características externas" de un delirio se vienen a cumplir de todos modos en el caso que nos ocupa.

Hay extensos ejemplos en la novela de cómo el protagonista hacía uso de interpretaciones delirantes y alte- 
raciones sensoperceptivas para extender y sistematizar su delirio, lo que vienen a ser otros dos aspectos formales básicos del desarrollo paranoide que describimos en Don Quijote.

2.3.d. Uso de interpretaciones erróneas para la progresión del delirio.

El delirio, que comienza como una idea sobrevalorada, va adquiriendo consistencia y organizándose por continuidad, contigüidad y semejanza al resto de situaciones, lugares y personas que inicialmente habían sido preservadas de ser incluidas en el delirio. Esto sucede a base de interpretaciones erróneas que justifican la temática central del delirio, ya se trate de ilusiones (alteraciones senso-perceptivas) o interpretaciones delirantes propiamente dichas (juicio erróneo montado sobre una percepción exacta).

En los primeros capítulos de la novela de 1605 se puede seguir con claridad este proceso. Así, en su capítulo primero, Cervantes da cuenta de lo que podría calificarse como ideas sobrevaloradas en la mente del hidalgo manchego: " $y$ asentósele de tal modo en la imaginación que era verdad toda aquella máquina de aquellas sonadas soñadas invenciones que leía, que para él no había otra historia más cierta en el mundo. Decía él que el Cid Ruy Díaz había sido muy buen caballero, pero que no tenía que ver con el Caballero de la Ardiente Espada, ..." (79). Con el devenir de sus aventuras, la nómina de situaciones y personajes que se ven incluidos en su delirio se amplía, así por ejemplo sucede a su llegada a la venta donde será armado caballero: “ $y$ como a nuestro aventurero todo cuanto pensaba, veía o imaginaba el parecía ser hecho y pasar al modo de lo que había leído, luego que vio la venta se le representó que era un castillo con sus cuatro torres..." (80). Le siguen otras tantas ilusiones de la vista, del tacto y del olfato, así como numerosos ejemplos de interpretaciones delirantes que se han comentado en el apartado precedente.

\section{3.e. Sistematización del delirio.}

A diferencia de lo observado en los delirios esquizofrénico, parafrénico y de los procesos cerebrales orgánicos, donde los contenidos delirantes aparecen ante el observador con una estructura disgregada y paralógica, el delirio del paranoico es coherente, carente de saltos lógicos o asociativos. Esto es así porque existe un curso de pensamiento preservado, lo que le constituye su rasgo más distintivo entre los diferentes trastornos mentales que cursan con ideación delirante. Al observador le resulta difícil encontrar contradicciones internas en el relato que permitan diferenciarlo de un hecho real.

En el caso de nuestro personaje, nada más fiel a la figura de un caballero andante que la forma que elige Don Quijote de emularlo, sin ningún detalle que falte a la coherencia interna de lo que reflejan los libros de donde toma su referente. El caballero andante se nos presenta con todos los elementos propios de su imaginada condición: armadura, rocín y escudero. "Limpias, pues, sus armas, hecho del morrión celada, puesto nombre a su rocín y confirmándose a sí mismo, se dio a entender que no le faltaba otra cosa sino buscar una dama de quien enamorarse; porque el caballero andante 
sin amores era árbol sin hojas y sin fruto y cuerpo sin alma" (81). Asimismo, cuida de elegir un nombre novelesco para todos ellos y sus enemigos, los imprescindibles "encantadores", elige un lenguaje arcaico para sus discursos "iba ensartando otros disparates, todos al modo que sus libros le habían enseñado, imitando en cuanto podía su lenguaje” (82). Tampoco falta coherencia interna a su actitud desafiante y temeraria frente a todos los agravios que cree percibir, ejemplificada en tantas hazañas violentas, y sus rituales de sumisión y ofrecimiento a Dulcinea del Toboso, que alcanzan su máxima expresión en los capítulos XXV y XXVI de la primera parte, donde decide hacer "imitación a la penitencia de Beltenebros": se aísla en Sierra Morena para emular a Amadís "que sin hacer locuras de daño, sino de lloros y sentimientos, alcanzó tanta fama como el que más” (83) y siguiendo el modelo de los más famosos caballeros andantes, envía a Dulcinea una carta de amor a través de su escudero, para que ésta tenga noticia de su desenfrenado amor por ella.

\section{3.f. El delirio carece del carácter de} vivencia impuesta.

Si bien Don Quijote puede llegar a explicitar su voluntad de seguir un modelo contenido en los libros de caballerías, como es el capítulo recién comentado donde hace penitencia por su amada, no muestra dudas en ningún momento de que la vivencia que está atravesando es propia y no tiene carácter de imposición, como ocurre en el delirio de los esquizofrénicos. Todos sus actos psíquicos ( pensamientos, sentimientos, creencias, recuerdos, per- cepciones, etc...) los vive como suyos, al igual que cualquier persona sana. No se llega a dar lo que López Ibor denominó "la inversión de la flecha intencional” (84), referido al fenómeno específicamente esquizofrénico de que las intenciones proceden de fuera y se dirigen a él, son pensamientos inspirados en una especie de revelación que, según Alonso Fernández “domina y subyuga al yo" (85).

\section{3.g. Carácter centrípeto y autorreferencial \\ El delirio esquizofrénico para-} noide comparte esta característica con el paranoico. Ambos se sienten, según describiera Henri Ey, "el ombligo del mundo", y por tanto todo lo que le rodea contribuye a argumentar a favor de su delirio, tanto lo que es como lo que no es accesible a sus sentidos.

2.3.h. El tema persecutorio como tema común a todos los contenidos delirantes.

Si bien son muchos los contenidos delirantes que se pueden identificar en el Caballero de la Triste Figura, Kraepelin (86), como en todo caso de paranoia, los reduciría a dos: el perjuicio y la grandeza. Henri Ey (87) va más lejos, sugiriendo que todos los temas delirantes son reductibles a una sola fórmula fundamental: el contenido persecutorio. Esto puede llegar a resultar contradictorio en el caso de los contenidos delirantes megalomaniacos, como se dan en el hidalgo manchego. En estos casos, Ey y Cabaleiro (88) opinan que, a pesar de la temática grandiosa, el delirante se sentirá envidiado o se verá obligado a demostrar su valía frente a un entorno hostil plagado de enemigos que intentan difamarle. 
No resulta difícil encontrar ejemplos de este último aspecto a lo largo de la novela. El más conocido suceso, acaecido en la aventura de los molinos de viento, lo ilustra extensamente. Encontrándose ya en el suelo nuestro protagonista, le viene a explicar a Sancho que "cuanto más, que yo pienso, y es así verdad, que aquel sabio Frestón que me robó el aposento y los libros ha vuelto estos gigantes en molinos, por quitarme gloria de su vencimiento: tal es la enemistad que me tiene; mas al cabo al cabo, han de poder poco sus malas artes contra la bondad de mi espada" (89).

\subsection{Diagnóstico diferencial}

El trastorno delirante puede considerarse diferente de otros trastornos geriátricos donde aparecen también fenómenos psicóticos. De entre ellos, cabe el diagnóstico diferencial con los trastornos referidos a continuación.

\section{4. a. Esquizofrenia de inicio tardío} (Parafrenia)

Este es el trastorno donde la diferenciación se hace más difícil, incluso llega a ser prácticamente imposible en determinados pacientes. El caso de Don Quijote es uno de ellos.

Se trata de un cuadro psicótico de comienzo tardío con gran riqueza alucinatoria y delirante y ausencia de deterioro, por lo que se situaría entre la esquizofrenia y el trastorno delirante.

Es un trastorno cuyo status como entidad nosológica independiente ha sido históricamente controvertido. La primera descripción de esta entidad clínica ( parafrenia) corresponde a Kraepelin, quien había reunido una serie de cuadros clínicos de inicio tardío caracterizados por un delirio alucinatorio mal sistematizado, de fondo persecutorio, que evolucionaban con ausencia del deterioro observado en la dementia praecox. Bleuler, en 1911, amplía el concepto de esquizofrenia, por lo que se vio innecesario mantener a la parafrenia como entidad independiente. Posteriormente, con Mayer-Gross, la psiquiatría alemana le niega autonomía nosológica y el propio Kraepelin la elimina de su texto en la edición de 1926.

La psiquiatría francesa, no obstante, ha reconocido siempre esta entidad. Ey, en 1975, defiende la independencia de las parafrenias en función de sus propias características clínicas, la buena adaptación social y ausencia de deterioro.

La psiquiatría anglosajona, tras rechazar inicialmente el concepto de parafrenia, lo rescata en 1952 a cargo de Roth y Morrisey y usan el termino de parafrenia y parafrenia tardía de forma puramente descriptiva, al estilo de Kraepelin, sin relación con la etiología. A pesar de la polémica generada, el término se usa en el Reino Unido como un diagnóstico que cubre todas las formas de psicosis de aparición tardía distintas de la demencia o de la depresión delirante, y engloba tanto los trastornos más cercanos a la esquizofrenia como los trastornos delirantes.

En lo referido a las clasificaciones internacionales (DSM-IV y CIE-10), ninguna de ellas contempla diagnósticos separados para esta entidad. Todos los casos que cumplan criterios para esquizofrenia, independientemente de la edad de inicio, caen en la misma categoría diagnóstica.

Recientemente, con el fin de unificar criterios, en 1998 se promovió una Conferencia Internacional sobre 
Esquizofrenia y Psicosis Tardías cuyas conclusiones de consenso fueron publicadas por Howard.R. y cols en el 2000 (90). Se adoptaron los términos de Esquizofrenia de aparición tardía (late-onset shizophrenia), de inicio a partir de los 40 años y Psicosis de tipo esquizofrénico de aparición muy tardía (very-late-onset schizophrenia-like psicosis), de inicio a partir de los 60 años. Se considera que ambas entidades tienen validez y utilidad clínica en términos de epidemiología, perfil sintomático y patofisiología. Los diagnósticos hacen referencia a psicosis de aparición en edades avanzadas sin antecedentes delirantes previos y sin relación con la demencia o los trastornos afectivos.

El cuadro clínico difiere de la esquizofrenia de inicio temprano. En la esquizofrenia de aparición tardía, los autores encuentran mayor tendencia a padecer alucinaciones visuales, táctiles, olfatorias y auditivas, estas últimas de tipo acusatorio en tercera persona. También hay una riqueza delirante de contenido persecutorio y menor presencia de alteración formal de lenguaje o aplanamiento afectivo.

En la psicosis de tipo esquizofrénico de aparición muy tardía, las alucinaciones visuales son más frecuentes y la aparición de trastornos formales del pensamiento o sintomatología negativa es excepcional.

Algunas de las similitudes y diferencias entre esquizofrenia tardía y trastorno delirante quedan reflejadas en la tabla 1 (91).

En negrita están señaladas las características que se cumplen en el caso de Don Quijote, lo que favorece más bien al diagnóstico de trastorno delirante pare éste. El criterio básico que inclina el diagnóstico del ingenioso hidalgo a este tipo de cuadro es la ausencia de una riqueza alucinatoria parafrénica y el contenido delirante bien sistematizado, sin ser de contenido fantástico o variable como en la parafrenia.

Factores a favor de que se tratara de una esquizofrenia tardía o parafrenia son el inicio a los 50 años, la personalidad preservada y la ausencia de alteraciones formales del pensamiento, afecto aplanado o embotado. No obstante, estos son rasgos que comparte con el trastorno delirante. El único punto a favor de una esquizofrenia tardía es el referido al pronóstico, que es más favorable y coincide con la completa recuperación clínica del hidalgo manchego al final de la novela.

\section{4. b. Demencia}

Este es un diagnóstico a considerar en todo paciente de edad avanzada con ideación delirante, como es el caso que nos ocupa. Se trata de un síndrome adquirido, de naturaleza orgánica, caracterizado por un deterioro permanente de la memoria y de otras funciones intelectuales y frecuentemente se presenta acompañado de otras manifestaciones psicopatológicas; ocurre sin alteración del nivel de conciencia y afecta al funcionamiento social y ocupacional (92).

La psicopatología acompañante comprende alucinaciones y delirios semejantes a los de un cuadro psicótico ( bien sea una paranoia o una parafrenia), pero en general las de la demencia son más simples, transitorias y aparecen en fases menos precoces de la enfermedad.

En cuanto al déficit cognitivo, cabe señalar que, por lo general, los 
procesos demenciantes no afectan a todas las capacidades intelectuales con igual gravedad, lo que permite su clasificación y diferenciación clínicas. Los tres tipos básicos de demencia son las corticales ( incluye E. Alzheimer, Demencia frontotemporal y Demencia por Cuerpos de Lewy), las subcorticales y las córticosubcorticales (93).

Demencia por cuerpos de Lewy.

Para el diagnóstico diferencial de Don Quijote, cabe detenerse especialmente en una de demencias de afectación cortical: la demencia por cuerpos de Lewy. Ésta es una entidad definida por el hallazgo histológico de pérdida neuronal e inclusiones neuronales basófilas ( cuerpos de Lewy) en la corteza cerebral, en un paciente con demencia. La primera descripción de estas inclusiones basófilas la realizó Friedrich Lewy en la enfermedad de Parkinson en 1912. El diagnóstico de esta entidad se consolidó en 1996, al publicarse los criterios de consenso por parte de todos los grupos de trabajo interesados en esta enfermedad (94).

El cuadro clínico permite especular que Don Quijote padeciera este tipo de proceso, como lo han señalado algunos autores recientemente (García Ruíz y Gulliksen) (95). Sus rasgos esenciales consisten en un síndrome demencial con fluctuaciones, síntomas psicóticos y parkinsonismo.

1. Deterioro cognitivo: se caracteriza por su variabilidad y por afectar a funciones ejecutivas de tipo frontosubcortical, la memoria, la fluencia verbal y la praxis constructiva y visuoespacial. Es destacable un déficit grave en la capacidad atencional, que puede condicionar episodios confusionales breves. Las fluctuaciones en el grado de afectación cognitiva permiten momentos de mayor lucidez, en los que el paciente puede reconocer la presencia de su trastorno y su variabilidad.

En el personaje de Don Quijote, estos episodios confusionales breves se pueden observar (Cap. VII, Primera parte), pero no hay evidencia de un deterioro cognitivo como el que se requiere para el diagnóstico de esta entidad. En cuanto a los episodios de lucidez intercalados entre los momentos más delirantes (Cap. I, Segunda parte), son más bien compatibles con la presencia de un delirio encapsulado en Don Quijote, cuya paranoia no le impide mantener su personalidad y funciones intelectuales conservadas. El hidalgo manchego nunca llega a reconocer su trastorno durante estos intervalos lúcidos, sino más bien al final, cuando todo el cuadro psicótico ha remitido.

2. Síntomas psicóticos: lo más prominente es la presencia de alucinaciones visuales frecuentes, persistentes, bien estructuradas, vívidas y detalladas. Se presentan en episodios recortados y la respuesta a ellas puede variar desde el miedo, la indiferencia o la interacción alegre con éstas. Por lo general existe cierta conciencia de su irrealidad tras haberlas padecido. Otros síntomas más inespecíficos son alucinaciones de otros sentidos, así como delirios bien estructurados (en un 65\% de casos) sobre la base de estas alteraciones perceptivas. Los síntomas depresivos son frecuentes (35-50\%).

El caso que nos ocupa no es compatible con este perfil de síntomas psicóticos, ya que las alucinaciones no 
predominan en Don Quijote salvo durante los breves episodios confusionales ya mencionados. El delirio que se estructura en la mente del ingenioso hidalgo no surge alrededor de alteraciones perceptivas sufridas previamente y nunca se da un momento de crítica tras padecerlas. En cuanto a la clínica depresiva, cabe mencionar que su aparición coincide con la remisión del cuadro psicótico y no durante el mismo.

3. Síntomas parkinsonianos: en un $77 \%$ de pacientes, éstos aparecen tras el establecimiento del deterioro cognitivo. Lo más común es la presencia de rigidez y bradicinesia.

Éste es un hallazgo que no menciona Cervantes en ningún momento de su novela.

4. Otros síntomas: éstos contribuyen a confirmar el diagnóstico. Entre ellos se encuentran trastornos autónomos ( p.ej. hipotensión), caídas, síncopes, mioclonías y alteraciones del sueño REM.

Sólo cabe mencionar este último rasgo clínico referido al sueño REM, por cuanto García Ruiz y Gulliksen lo señalan como argumento a favor de este diagnóstico en Don Quijote. En el Capítulo 35 de la primera parte, el hidalgo loco es hallado en plena batalla contra los gigantes "no tenía los ojos abiertos, porque estaba durmiendo y soñando que estaba en batalla con el gigante" (96). Éste no deja de ser un síntoma inespecífico que requiere de la presencia de todos los demás rasgos clínicos descritos para poder catalogar el trastorno de Don Quijote como una demencia por cuerpos de Lewy.
3. DQ y Sancho: un caso de Trastorno psicótico compartido (folie à deux)

El Trastorno psicótico compartido es el nombre que la nosología actual americana ( DSM-IV) reserva para un cuadro clínico descrito ya en 1860 por Baillarger (folie a communiquée) y que recibió su denominación más conocida, la de folie à deux, a cargo de Ernest Charles Lasègue y Jules Falret en 1877 (97). La CIE-10 lo incluye dentro del Trastorno de ideas delirantes inducidas (F 24) junto con el Trastorno paranoide inducido y la Psicosis simbiótica.

Se trata de un cuadro de infrecuente aparición y los criterios que se consideran necesarios para identificarlo los recoge la nosología americana (DSM-IV) en tres puntos:

A. Se desarrolla una idea delirante en un sujeto en el contexto de una relación estrecha con otra(s) persona(s) que ya tiene(n) una idea delirante establecida.

B. La idea delirante es parecida en su contenido a la de la persona que ya tiene la idea delirante

C. La alteración no se explica mejor por la presencia de otro trastorno psicótico (por ejemplo, esquizofrenia) o de un trastorno del estado del ánimo con síntomas psicóticos, y no es debida a los efectos fisiológicos directos de alguna sustancia (por ejemplo, una droga, un medicamento) o una enfermedad médica.

Existen cuatro tipos diferentes de folie que tienen más interés histórico que clínico y fueron la aportación de Marandon de Montyel y Heinz Lehmann. El más frecuente es el de la folie imposée o impuesta ( caso del escudero Sancho) y 
otras son la folie simultanée ( simultánea), folie communiquée ( transmitida) y folie induite (inducida) (98).

En el caso que nos ocupa, Don Quijote actúa como sujeto dominante y desarrolla un sistema delirante que impone (folie imposé) progresivamente a su escudero, sujeto sumiso.

La principal hipótesis etiológica para este cuadro clínico es psicosocial y señala los siguientes factores predisponentes:

1. El sujeto dominante suele ser mayor, más inteligente y culto. Asimismo, posee unos rasgos de personalidad más fuertes que la persona sumisa.

2. El sujeto sumiso puede estar predispuesto a un trastorno mental y su personalidad muestra rasgos de dependencia y sugestionabilidad. A través de un proceso de identificación con el dominante, adopta sus síntomas para obtener su reconocimiento.

3. La relación entre ambos sujetos es muy estrecha, de tipo emocional, asociada a experiencias vitales compartidas, necesidades y esperanzas comunes. Suele darse en el aislamiento total o parcial de influencias sociales y culturales exteriores (99).

Todos estas características las reúnen ambos personajes, ya que Don Quijote es un hidalgo cultivado de mayor nivel socio cultural que su escudero, hombre sencillo del campo con pocos recursos económicos y culturales, así como escasa asertividad e ingenuidad profunda. Ambos llevan a cabo sus andanzas en casi completa soledad y la vinculación afectiva entre ambos se va enraizando a medida que avanza la novela y que el trastorno psicótico compartido hace su aparición.
Asimismo, ya se ha mencionado cómo algunos de los rasgos formales del delirio de Don Quijote favorecen el contagio del buen entendimiento de su escudero Sancho. Tres de ellos son esenciales:

1. La personalidad del protagonista, como sucede en todo paranoico, está preservada.

2. El delirio se presenta al observador de una forma coherente y sistematizada, gracias a que el curso del pensamiento en quien lo padece no ha sufrido alteración alguna. No sin acierto, Pinel denominó a este trastorno la "locura razonante". Numerosos ejemplos de esto los encontramos en los discursos de Don Quijote, como en el "las armas y las letras" en el capítulo XXXVIII de la primera parte.

3. Existe una alta carga de afectividad asociada a la narración y la conducta del delirante. En el capítulo XVIII, en que el protagonista se altera con la visión de dos manadas de ovejas, "con tanto ahínco afirmaba don Quijote que eran ejércitos, que Sancho lo vino a creer, y a decirle:

-Señor, pues, ¿qué hemos de hacer nosotros?" (100).

Todo esto viene a favorecer que Don Quijote establezca relaciones empáticas con quienes le rodean y hacen que el delirio se pueda transmitir a personas sanas. Esta es la razón por la que Serieux y Capgras (101) denominaron al trastorno delirante (que ellos denominaban "delirio de interpretación") la "psicosis persuasiva" y la pareja protagonista de la inmortal novela cervantina es un claro ejemplo de ello. 
El desarrollo de los síntomas de Sancho se puede seguir a lo largo de la novela como reflejo de la locura de su protagonista. Su culminación se da cuando éste recupera finalmente el juicio y se dirige a él en su lecho de muerte: "Perdóname, amigo, de la ocasión que te he dado de parecer loco como yo, haciéndote caer en el error en que yo he caído, de que hubo y hay caballeros andantes en el mundo"- a lo que el escudero responde: “...Mire no sea perezoso, sino levántese desa cama, y vámonos al campo vestidos de pastores, como tenemos concertado: quizá tras de alguna mata hallaremos a la señora doña Dulcinea desencantada, que no haya más que ver. $\mathrm{Si}$ es que se muere de pesar de verse vencido, écheme a mí la culpa, diciendo que por haber yo cinchado mal a Rocinante le derribaron; cuanto más que vuestra merced habrá visto en sus libros de caballerías ser cosa ordinaria derribarse unos caballeros a otros, y el que es vencido hoy ser vencedor mañana" (102). Sancho le sigue animando en sus planes apragmáticos en la convicción de ser el escudero de un auténtico caballero andante.

\section{Conclusiones}

La literatura crítica sobre El Quijote es muy vasta e incluye tanto aproximaciones desde la filología hasta estudios elaborados desde una perspectiva médico-psiquiátrica, estos últimos surgidos desde el S. XIX. Desde sus inicios, esta línea de estudio calificó el tipo de locura que afecta a Don Quijote como un cuadro de paranoia, lo que inicialmente fue denominado monomanía y la nosología actual califica de trastorno delirante. También se han dado aproximaciones a la biotipología de los personajes que emparejan a los dos protagonistas, Don Quijote y Sancho, con los biotipos leptosómico (temperamento esquizotímico) y pícnico (temperamento ciclotímico) de Kretschmer, respectivamente.

La locura de Don Quijote reúne todos los criterios clínicos necesarios para diagnosticarlo según la nosología actual de trastorno delirante ( DSM-IV) o trastorno por ideas delirantes persistentes ( CIE-10). Asimismo, los clásicos, empezando por Pinel a principios del S. XIX, coincidieron en opinar que la afección del personaje era la entonces llamada monomanía, correspondiente a la posterior paranoia de Kraepelin.

La génesis del delirio en Don Quijote obedece a la descripción realizada por Kretschmer para lo que él denominó el delirio sensitivo de referencia. Éste es un modelo explicativo muy aplicable al trastorno delirante y postula la confluencia de un tipo de personalidad predisponente para el delirio ( la personalidad sensitiva) bajo un entorno social concreto y tras un acontecimiento vital estresante. Todos estos factores se pueden rastrear en la novela del ingenioso caballero andante y corroboran el diagnóstico históricamente propuesto para él.

La sintomatología también conforma a lo largo de toda la obra los rasgos distintivos de este trastorno mental, sobre todo en lo que a las alteraciones del contenido del pensamiento se refiere. Éstas consisten en ideación delirante estructurada de tipo básicamente grandioso, pero también de tipo persecutorio y erotomaniaco. 
Otro hallazgo psicopatológico relevante es la presencia de interpretaciones delirantes y falsas identificaciones, las cuales contribuyen en la extensión y sistematización del delirio de base. En este último aspecto influye también la existencia de ilusiones, las cuales vienen a ser las alteraciones sensoperceptivas predominantes. Las alucinaciones también se dan en ocasiones, siendo compatibles con el diagnóstico de trastorno delirante, ya que son acordes con el delirio.

Sobre el humor cabe decir que está marcado por el tipo de contenido delirante que predomine, siendo la tendencia a la hipertimia, pero sin llegar a darse criterios para un trastorno afectivo mayor. También se presenta un episodio de ánimo bajo al final de la novela, coincidiendo con el momento en que el protagonista hace crítica de la ideación delirante y cobra una conciencia de enfermedad que no había tenido hasta entonces.

La estructura formal del delirio de Don Quijote reúne también las características para calificarlo como un trastorno delirante. El análisis de su delirio, según los planteamientos originales de Jaspers, revela que es de carácter secundario, no es un tipo de vivencia "impuesta" que caracteriza al delirio de un esquizofrénico. Esto es así ya que la personalidad premórbida del hidalgo manchego hace que los síntomas debuten de forma insidiosa y acorde con los rasgos caracteriales previos (carácter constitucional del delirio).
Cabe destacar también que el contenido delirante se puede reducir a lo persecutorio y esto matiza la aparición de una vivencia centrípeta o autoreferencial del entorno. A medida que se van dando diversas interpretaciones erróneas e ilusiones auditivas, visuales o táctiles, el contenido delirante se sistematiza hasta un considerable grado de complejidad.

El grado de afectividad asociado al delirio es elevado, lo que impele al personaje a la acción y a la persuasión de las personas de su entorno, favoreciendo la aparición de un "delirio a dos".

Por sus características clínicas, el cuadro clínico de Don Quijote permite hacer el diagnóstico diferencial con la parafrenia y con la demencia, en concreto la enfermedad por cuerpos de Levy.

La extensión del delirio de Don Quijote a su escudero Sancho es compatible con la formulación diagnóstica de Trastorno psicótico compartido (DSM-IV), más conocido como folie à deux. Se trataría de una forma impuesta de folie, donde el escudero actúa como sujeto sumiso debido a sus rasgos psico-sociales y caracteriales y a la relación emocionalmente estrecha y aislada que ambos mantienen. Asimismo, la preservación de la personalidad y del curso de pensamiento en Don Quijote, así como el carácter afectivo de su delirio, facilitan un grado de empatía y persuasión en las personas su entorno, especialmente en Sancho. 
Tabla 1.

\begin{tabular}{|c|c|c|}
\hline & $\begin{array}{l}\text { TRASTORNO } \\
\text { DELIRANTE }\end{array}$ & $\begin{array}{l}\text { ESQUIZOFRENIA } \\
\text { TARDÍA }\end{array}$ \\
\hline Genética & $\begin{array}{l}\text { Cierto mayor riesgo de } \\
\text { esquizofrenia que en } \\
\text { población general }\end{array}$ & Similar hallazgo \\
\hline Distribución por sexos & Varones más frecuente & Mujeres más frecuente \\
\hline Epidemiología & Muy poco frecuente & Algo más frecuente \\
\hline Déficit sensoriales & Factor de riesgo & $\begin{array}{l}\text { Factor de riesgo. } \\
\text { Hallazgo más frecuentes }\end{array}$ \\
\hline Síntomas de primer orden & Ausentes & Presentes \\
\hline Personalidad premórbida & Paranoide & Paranoide o esquizoide \\
\hline Delirios & Persecutorios & Persecutorios y otros \\
\hline Alucinaciones & $\begin{array}{l}\text { Ausentes o poco } \\
\text { predominantes }\end{array}$ & $\begin{array}{l}\text { Frecuentes, vivas y en } \\
\text { varias modalidades }\end{array}$ \\
\hline Afectividad & Conservada & $\begin{array}{l}\text { Conservada. Si hay } \\
\text { síntomas depresivos } \\
\text { son 2rios }\end{array}$ \\
\hline Marcadores biológicos & Escasos & $\begin{array}{l}\text { Alteraciones cerebrales } \\
\text { estructurales } \\
\text { y funcionales }\end{array}$ \\
\hline Curso & Crónico sin deterioro & Crónico sin deterioro \\
\hline Respuesta al tratamiento & Escasa & Parcial o completa \\
\hline
\end{tabular}




\section{BIBLIOGRAFÍA}

1. Tabarés-Seisdedos, R; Corral-Márquez, R. Am J Psychiatry 158:9, 2001

2. Miguel de Unamuno. La locura de Don Quijote. Salamanca. 10-IV-1905

3. D. Martinez Torrón. "La locura de Don Quijote. Ideología y literatura en la novela cervantina”. Anales Cervantinos. 1998, 34. pp 23-36.

4. Ibid

5. R. Bartra. "Melancolía y cristianismo. Sobre la tristeza de Don Quijote". En: R.Bartra. Cultura y melancolía. Las enfermedades del alma en la España del Siglo de Oro. Ed. Anagrama. Barcelona 2001

6. D. Martinez Torrón. "La locura de Don Quijote. Ideología y literatura en la novela cervantina”. Anales Cervantinos. 1998, 34. pp 23-36.

7. Ibid.

8. M. De Cervantes. El ingenioso caballero Don Quijote de la Mancha. Segunda parte. Ed. Cátedra. Madrid, 2000. pp 43.

9. J. Jay Allen. "La crítica". En: M. De Cervantes. El ingenioso caballero Don Quijote de la Mancha. Introducción. Ed. Cátedra. Madrid, 2000. pp.29-37.

10. L. S. Granjel. "Los médicos ante el Quijote". Medicina e Historia. 1976. Nr. 53, pp 8-25.

11. A. Vallejo Nágera. "Apología de las patografías cervantinas". Discurso leído en la Fiesta del Libro Español celebrada por el Instituto de España; Imp. Góngora; 41pp; Madrid, 1958.

12. J.López Piñero. Antología de Clásicos Médicos. Ed. Triacastela. Madrid, 1998. pp 182.

13. Theophile Roussel le consideró "monomaníaco alucinado". Louveau ( De la manie dans Cervantes, Montpellier, 1876) y Ville Chauvaix ( Cervantes malade et médecin, Paris 1898) le dedicaron sendos trabajos doctorales. J M Guardia, médico español nacionalizado francés, también publica Le portrait de Cervantes en 1866 y comenta la edición francesa del estudio de Hernández Morejón en 1862.

14. Madrid, Imp. Tomás Jordán, 1836. Actualmente en Historia bibliográfica de la Medicina Española; Madrid, 1845. tomo II, pp 166-180., con el título "Bellezas de la medicina práctica descubiertas en la obra de Cervantes".

15. Cabe mencionar también las contribuciones de autores no españoles como el psiquiatra alemán Wilhelm Weygand ( citado por R.Sarró en "El corazón humano visto a través de la locura"; Jano; Nr. 187. Barcelona. 1975), y los franceses Genel-Perrin ( "Don Quichotte paranoiaque et le Bovarysme de Don Quichotte"; Mercure de France; CCLXII, 892: 45-57; Paris, 1935), M. Pestel ("L'étrange psychose de Don Quichotte: essai sur un idealisme engagé". Presse Médicale; 72: 3407-12. Paris, 1964) y H. Couleon ( "L'étrange folie de Don Quichotte. Cervantes et la psychiatrie". Ann.méd. Psicol..; 122,1:555-66; Paris, 1964).

16. Madrid, Imp. Tomás Jordán, 1836. Actualmente en Historia bibliográfica de la Medicina Española; Madrid, 1845. tomo II, pp 166-180., con el título Bellezas de la medicina práctica descubiertas en la obra de Cervantes

17. M. De Cervantes. El ingenioso caballero Don Quijote de la Mancha. Primera parte. Cap. I. pp 100. Ed. Cátedra. Madrid, 2000

18. Costa Molinari. "Emilio Pi y Molist" ( 1824-1892). En: Anthology of spanish psychiatric texts. Edited by J. López Ibor. WPA.2001. pp 111-113.

19. E. Pi y Molist. Primores del Don Quijote en el concepto médico-psicológico y consideraciones generales sobre la locura para un nuevo comentario de la inmortal novela. Imp. Barcelonesa; Barcelona 1886. 
ORIGINALES Y REVISIONES

20. Ibid. Cap. V. "Diagnóstico de la locura de Don Quijote por sus síntomas elementales". pp. 91-111

21. Royo Villanova. La locura de Don Quijote Imp. De E. Cañasal; Zaragoza, 1905.

22. Royo Villanova Don Quijote, licenciado en Medicina Tip. De Cañasal. 12 pp.; Zaragoza, 1916

23. R. Salillas. Un gran inspirador de Cervantes. El doctor Juan Huarte y su "Examen de Ingenios; p.31; Lib. De V.Suárez; Madrid, 1905.

24. J. Goyanes. Capdevila. Tipología de El Quijote. Ensayo sobre la estructura psicosomática de los personajes de la novela; Prólogo del Dr. Gregorio Marañón; S. Aguirre, imp.; xvi-297 pp.; Madrid, 1932.

25. Ibid. pp $4-5$

26. Ibid. pp 30

27. Ibid. pp 25

28. Ibid. pp 147

29. Ibid. pp 4-5

30. C. Gutiérrez-Noriega. "Contribución de Cervantes a la Psicología y la Psiquiatría" Rev. De Neuro-Psiquiatría; VII: 149-93; Lima, 1944.

31. C. Gutiérrez-Noriega. "La personalidad y el carácter en la obra de Cervantes"; Rev. De Neuro-Psiquiatría; X: 516-41; Madrid, 1947

32. H. Kaplan, B. Sadock. Sinopsis de psiquiatría. $8^{\text {a }}$ edición. Madrid, 1999. pp580

33. E. Kraepelin. Lehrbuch der Psychiatrie. VI Edición. 1899.

34. C. Leal, J. Sanjuan, V. Balanza. "Nosología de los trastornos delirantes". En: Actualización en delirios. Ed. Aula Médica. Madrid. 2001. pp. 147-172

35. A. Díez Patricio. "La psicogénesis del delirio en la época de E.Kretschmer". Revista de la AEN.,2001,Vol XXI, 80.pp.73-97

36. Según D. Barcia, el propio Pinel interpretó la locura de D. Quijote "como una descripción admirable de monomanía". En: Historia de la psiquiatría española. Madrid, 1996. pp 228

37. M. Jesús García. Historia de la psiquiatría y de la asistencia psiquiátrica en Europa y en España desde sus orígenes hasta la actualidad. 1999. pp. 32.

38. E.Kretschmer. El delirio sensitivo de referencia. Contribución al problema de la paranoia y a la teoría psiquiátrica del carácter. Ed. Triacastela. Madrid, 2000

39. Ibid.

40. M. De Cervantes. El ingenioso caballero Don Quijote de la Mancha. Segunda parte. Ed. Cátedra. Madrid, 2000.Cap.LXXIV.pp. 575

41. A. Díez Patricio. "La psicogénesis del delirio en la obra y en la época de E. Kretschmer". Rev.Asoc. Esp.Neuropsiq.,2001, vol XXI, 80, pp 80.

42. E.Kretschmer. El delirio sensitivo de referencia. Contribución al problema de la paranoia y a la teoría psiquiátrica del carácter. Ed. Triacastela. Madrid, 2000

43. M. De Cervantes. El ingenioso caballero Don Quijote de la Mancha. Primera parte. Ed. Cátedra. Madrid, 2000. Cap.I. pp.103

44. Ibid. Segunda parte. Cap. I. pp 30-32.

45. Ibid. Primera parte. Cap. XIX. pp. 243

46. Ibid. Segunda parte. Cap.VII.pp.141

47. E. Pi y Molist. Primores del Don Quijote en el concepto médico-psicológico y consideraciones generales sobre la locura para un nuevo comentario de la inmortal novela. Imp. Barcelonesa; Barcelona 1886. pp.93

48. M. De Cervantes. El ingenioso caballero Don Quijote de la Mancha. Segunda parte. Ed. Cátedra. Madrid, 2000. Cap XXXII. pp. 273 
49. Ibid. Primera parte. Cap. LII. pp. 585

50. Ibid. Cap. VII. pp. 140

51. Ibid. Cap. XXXV. pp.432

52. H. Kaplan, B. Sadock. Sinopsis de psiquiatría. $8^{\text {a }}$ edición. Madrid, 1999. pp584

53. M. De Cervantes. El ingenioso caballero Don Quijote de la Mancha. Segunda parte. Ed. Cátedra. Madrid, 2000. Cap.XXXII. pp. 267

54. E. Kraepelin. Lehrbuch der Psychiatrie. VI Edición. 1899.

55. E. Pi y Molist. Primores del Don Quijote en el concepto médico-psicológico y consideraciones generales sobre la locura para un nuevo comentario de la inmortal novela. Imp. Barcelonesa; Barcelona 1886. pp. 97

56. P. Sánchez; E. Ruiz; I. Eguíluz. "Trastornos del contenido del pensamiento". En: Introducción a la psicopatología. Madrid, 2001. pp 112

57. M. De Cervantes. El ingenioso caballero Don Quijote de la Mancha. Primera parte. Ed. Cátedra. Madrid, 2000Cap. II. pp.107

58. Ibid. Cap.VIII. pp.145

59. Ibid. Cap. XVIII. pp. 228

60. Ibid. Cap. XXI. pp. 259

61. Ibid. Cap. XVI. pp.213

62. Ibid.

63. Ibid. Cap. XVIII. pp.232

64. Ibid. Cap.VII. pp. 139

65. E. Pi y Molist. Primores del Don Quijote en el concepto médico-psicológico y consideraciones generales sobre la locura para un nuevo comentario de la inmortal novela. Imp. Barcelonesa; Barcelona 1886. pp. 98

66. M. De Cervantes. El ingenioso caballero Don Quijote de la Mancha. Segunda parte. Ed. Cátedra. Madrid, 2000. Cap.XX. pp 172

67. H. Kaplan, B. Sadock. Sinopsis de psiquiatría. $8^{\text {a }}$ edición. Madrid, 1999. pp584

68. M. De Cervantes. El ingenioso caballero Don Quijote de la Mancha. Segunda parte. Ed. Cátedra. Madrid, 2000. Cap. LXXIV. pp 573.

69. Ibid. Primera parte.Cap. VII. pp.140.Cap. XXXV. pp.432

70. P.J.García Ruiz, L. Gulliksen. "Did Don Quixote have Lewy body disease?" J.R.Society of Medicine.1999.92:200-201

71. M. De Cervantes. El ingenioso caballero Don Quijote de la Mancha. Segunda parte. Ed. Cátedra. Madrid, 2000. Cap.LXXIV.pp. 572

72. K. Jaspers. Psicopatología General. Colección de Psicología, Psiquiatría y Psicoanálisis; 1993.

73. P. Sánchez; E. Ruiz; I. Eguíluz. "Trastornos del contenido del pensamiento". En: Introducción a la psicopatología. Madrid, 2001. pp. 144-152.

74. M. Cabaleiro Goas. Temas psiquiátricos. Ed. Paz Montalvo. Madrid, 1966

75. H. Ey. Estudios sobre los delirios. Ed. Paz Montalvo. Madrid, 1950.

76. C.Castilla del Pino. El delirio, un error necesario. Oviedo: Nobel.1998. pp.10

77. M. De Cervantes. El ingenioso caballero Don Quijote de la Mancha. Primera parte. Ed. Cátedra, Madrid, 2000. Cap. I. pp. 101

78. Ibid.

79. Ibid. pp. 100

80. Ibid. Cap. II. pp.107

81. Ibid. Cap. I. pp 102

82. Ibid. Cap. II. pp. 106 
83. Ibid. Cap.XXV. pp. 304

84. J. López Ibor. Los problemas de las enfermedades mentales. Ed. Labor. 1949.

85. F. Alonso Fernández. Fundamentos de la psiquiatría actual. Ed. Paz Montalvo. Madrid, 1976.

86. E. Kraepelin. Lehrbuch der Psychiatrie. VI Edición. 1899

87. H. Ey. Estudios sobre los delirios. Ed. Paz Montalvo. Madrid, 1950.

88. P. Sánchez; E. Ruiz; I. Eguíluz. "Trastornos del contenido del pensamiento". En: Introducción a la psicopatología. Madrid, 2001. pp.149

89. M. De Cervantes. El ingenioso caballero Don Quijote de la Mancha. Primera parte. Ed. Cátedra. Madrid, 2000. Cap VIII. pp. 146.

90. Howard, R. and cols. "Late-Onset-Schizophrenia and Very-Late-Onset Schizophrenia-Like Psicosis: An International Consensus". Am J Psychiatry 157:2, February 2000

91. Agüera Ortiz, L. "Esquizofrenia tardía". En: Psiquiatría geriátrica. Masson. Barcelona, 2002. pp 404.

92. SEP. Consenso Español de Demencias. Madrid: Drug Pharma, 2000

93. Martín Carrasco, M. "Las demencias". En: Psiquiatría geriátrica. Masson. Barcelona, 2002. pp 201

94. McKeith IG, Galasko D, Kosaka K, Perry EK, Dickson DW, Hansen LA y cols., "The Consortium on Dementia with Lewy Bodies. Consensus guidelines for the clinical and pathologic diagnosis of dementia with Lewy bodies ( DLB): Report of The Consortium on DLB International Workshop". Neurology 1996; 47: 1113-1124

95. García Ruíz, P.J., Gulliksen, L. "Did Don Quixote have Lewy body disease?". J $R$ Soc Med 1999; 92:200-201

96. M. De Cervantes. El ingenioso caballero Don Quijote de la Mancha. Primera parte. Ed. Cátedra. Madrid, 2000. Cap.XXXV. pp. 430

97. H. I. Kaplan, B. J. Sadock. Sinopsis de Psiquiatría. $8^{\text {a }}$ Edición.Ed. Panamericana. Madrid. 1999 pp. 563.

98. Ibid

99. Ibid

100. M. De Cervantes. El ingenioso caballero Don Quijote de la Mancha. Primera parte. Ed. Cátedra. Madrid, 2000. Cap XVIII. pp. 228

101. P. Serieux, J. Capgras. Las folies raisonnantes, Le délire d'interpretation. Ed. Alcan. Paris, 1909

102. M. De Cervantes. El ingenioso caballero Don Quijote de la Mancha. Segunda parte. Ed. Cátedra. Madrid, 2000. Cap LXXIV. pp. 575

\section{AUTORES:}

*Residente Psiquiatría. Hospital Clínico Universitario, Valencia

**Profesor Titular. Unidad Docente Psiquiatría y Psicología Médica.

Departament de Medicina. Universitat de València.

Avda. Blasco Ibáñez 15. 46010 Valencia. Email:

rafael.tabares@uv.es

(Autor al que debe dirigirse la correspondencia)

Fecha de recepción: 18-11-02 